\title{
Neisseria wadsworthii sp. nov. and Neisseria shayeganii sp. nov., isolated from clinical specimens
}

\section{Correspondence William J. Wolfgang wwolfgan@wadsworth.org}

\author{
William J. Wolfgang, ${ }^{1,2}$ Andrea N. Carpenter, ${ }^{1}$ Jocelyn A. Cole, ${ }^{1}$ \\ Sabine Gronow, ${ }^{3}$ Andrea Habura, ${ }^{2,4}$ Sherly Jose, ${ }^{1}$ Elizabeth J. Nazarian, ${ }^{1}$ \\ Donna J. Kohlerschmidt, ${ }^{1}$ Ronald Limberger, ${ }^{1,2}$ \\ Dianna Schoonmaker-Bopp, ${ }^{1}$ Cathrin Spröer ${ }^{3}$ and Kimberlee A. Musser ${ }^{1,2}$
${ }^{1}$ Wadsworth Center, Bacteriology Laboratory, New York State Department of Health, PO Box 22002, Albany, NY 12201, USA
${ }^{2}$ Department of Biomedical Sciences, State University of New York, Albany, NY 12201, USA D-38124 Braunschweig, Germany
${ }^{4}$ Wadsworth Center, Parasitology Laboratory, New York State Department of Health, PO Box 22002, Albany, NY 12201, USA \\ ${ }^{3} \mathrm{DSMZ}$ - Deutsche Sammlung von Mikroorganismen und Zellkulturen GmbH, Inhoffenstraße 7B,
}

\begin{abstract}
An analysis of 16S rRNA gene sequences from archived clinical reference specimens has identified two novel Neisseria species. For each species, two strains from independent sources were identified. Amongst species with validly published names, the closest species to the newly identified organisms were Neisseria canis, $N$. dentiae, $N$. zoodegmatis, $N$. animaloris and $N$. weaveri. DNA-DNA hybridization studies demonstrated that the newly identified isolates represent species that are distinct from these nearest neighbours. Analysis of partial 23S rRNA gene sequences for the newly identified strains and their nearest neighbours provided additional support for the species designation. Bayesian analysis of $16 \mathrm{~S}$ rRNA gene sequences suggested that the newly identified isolates belong to distinct but related species of the genus Neisseria, and are members of a clade that includes $N$. dentiae, $N$. bacilliformis and $N$. canis. The predominant cellular fatty acids [16:0, summed feature $3(16: 1 \omega 7 c$ and/or iso-15:0 2-OH) and $18: 1 \omega 7 c]$, as well as biochemical and morphological analyses further support the designation of Neisseria wadsworthii sp. nov. (type strain $9715^{\top}=\mathrm{DSM} 22247^{\top}=\mathrm{CIP} 109934^{\top}$ ) and Neisseria shayeganii sp. nov. (type strain $871^{\top}=$ DSM $22246^{\top}=$ CIP $109933^{\top}$ ).
\end{abstract}

In the present study, four clinical isolates received between 2004 and 2008, for which our laboratory was not able to provide a definitive species identification, were further characterized. During our routine reference identification, these isolates did not provide an acceptable percentage match to any available $16 \mathrm{~S}$ rRNA gene sequence in the MicroSeq (Applied Biosystems) and GenBank (http://www.

Abbreviation: CFA, cellular fatty acid.

The GenBank/EMBL/DDBJ accession numbers for the partial 16S rRNA gene sequence of strains $9715^{\top}, 2507,871^{\top}$ and 12337 are respectively FJ654662-FJ654665. The accession numbers for the partial 23S rRNA gene sequences of strains $12337,2507,9715^{\top}$, $871^{\top}$, N. canis ATCC $14687^{\top}, N$. weaveri DSM $17688^{\top}$, N. dentiae DSM $19151^{\top}, N$. animaloris DSM $21642^{\top}$ and N. zoodegmatis DSM $21643^{\top}$ are respectively FJ654666-FJ654670 and GU323335-GU323338.

A supplementary table and two supplementary figures are available with the online version of this paper. ncbi.nlm.nih.gov/entrez/) databases. The closest 16S rRNA gene sequence similarities ranged from 96 to $98 \%$, based on $500 \mathrm{nt}$ in the $5^{\prime}$ region of the gene. At the time of identification, strains $9715^{\mathrm{T}}$ and 2507 were identified as most closely resembling Neisseria canis. Strain $871^{\mathrm{T}}$ was identified as Neisseria sp. and strain 12337 was identified as most closely resembling CDC group EF-4b (now named Neisseria zoodegmatis; Vandamme et al., 2006).

To determine whether our isolates represented novel bacterial species, we performed a polyphasic study on these organisms and their phylogenetic neighbours. Identification of closely related species was initially carried out by using the BLAST (Altschul et al., 1997) and megaBLAST (Zhang et al., 2000) programs to compare nearly full-length $16 \mathrm{~S}$ rRNA gene sequences (1463 nt) of our isolates against the database of prokaryotic type strains with validly published names (Chun et al., 2007). The 50 
sequences with the highest scores were then selected for the calculation of pairwise sequence similarity using a global alignment algorithm, which was implemented at the EzTaxon server (http://www.eztaxon.org/; Chun et al., 2007). Previous studies have indicated that organisms with greater than $97 \% 16 \mathrm{~S}$ rRNA gene sequence similarity may represent the same species (discussed by Tindall et al., 2010). Therefore, we acquired all type strains with more than $97 \% 16 \mathrm{~S}$ rRNA gene sequence similarity to our isolates and have included them in our analysis. We employed 16S rRNA (1463 nt) and 23S rRNA (2093 and $2172 \mathrm{nt})$ gene sequence similarity, DNA-DNA hybridization, analysis of cellular fatty acid (CFA) composition, PFGE and phenotypic characterization to establish that our isolates represent two novel species of Neisseria.

The bacterial strains used in this study, their sources and the dates of isolation are listed in Table 1. All strains were grown at $37{ }^{\circ} \mathrm{C}$ in a $5 \% \mathrm{CO}_{2}$ atmosphere on trypticase soy agar (TSA) plates (Becton Dickinson) supplemented with $5 \%$ sheep blood. For CFA studies, the strains were grown in air at $37{ }^{\circ} \mathrm{C}$ on trypticase soy broth agar (TSBA) plates without sheep blood.

DNA for sequencing was prepared by heating a 1.0 McFarland standard suspension of the isolate to $95{ }^{\circ} \mathrm{C}$ in sterile distilled water for 15-20 min. The $16 \mathrm{~S}$ rRNA gene sequence was amplified using the forward primer 16S1 ( $5^{\prime}$ AGAGTTTGATCCTGGCTCAG-3', corresponding to Escherichia coli positions 8-27) and the reverse primer rp2 (5'-ACGGCTACCTTGTTACGACTT-3'; 1492-1512). Amplification was performed on an Icycler (Bio-Rad Laboratories) using AmpliTaq polymerase LD (Applied Biosystems) with a single cycle at $95{ }^{\circ} \mathrm{C}$ for 9 min followed by 40 cycles of $95{ }^{\circ} \mathrm{C}$ for $30 \mathrm{~s}, 60{ }^{\circ} \mathrm{C}$ for 1 min and $72{ }^{\circ} \mathrm{C}$ for $1.5 \mathrm{~min}$, followed by a final extension at $72{ }^{\circ} \mathrm{C}$ for 7 min and a $4{ }^{\circ} \mathrm{C}$ hold. PCR products were prepared for sequencing using ExoSAPIT (USB Corporation). The sequencing primers used were $\mathrm{pD}\left(5^{\prime}\right.$-CAGCAGCCGCGGTAATAC-3'), rpE (5'-CCGTCAATTCATTTGAGTTT$\left.3^{\prime}\right)$ and the two amplification primers. Nucleotide identities in each sequence represent two or more unambiguous calls from reads in both the forward and reverse directions. Polymorphisms (found only in isolate $871^{\mathrm{T}}$ ) are indicated by IUPAC code. A phylogenetic tree was constructed based on sequences retrieved from GenBank and aligned using a progressive alignment algorithm (CLC Main Workbench software 4.0; CLC Bio) with MrBayes 3.1.2 (Ronquist \& Huelsenbeck, 2003), $5 \times 10^{6}$ generations, using a GTR $+\mathrm{I}+\mathrm{G}$ substitution model with six rate categories. Two independent analyses were run, each consisting of four chains. Inspection of tree log-likelihood in this sample revealed that stationarity was reached after $2 \times 10^{6}$ generations, with the mean standard deviation of split frequencies stabilizing at $\sim 0.013$. These trees were discarded as burn-in, and the phylogenetic tree was constructed using the remaining $3 \times 10^{6}$ generations.

A comparison of $16 \mathrm{~S}$ rRNA gene sequences for strains $9715^{\mathrm{T}}$ and 2507 revealed $100 \%$ nucleotide similarity over $1463 \mathrm{nt}$, with no ambiguous nucleotides. The closest match based on 16S rRNA gene sequences (determined from the EzTaxon database; Chun et al., 2007) was Neisseria canis ATCC $14687^{\mathrm{T}}$ (Berger \& Paepcke, 1962), followed by Neisseria dentiae $\mathrm{V}_{3} 3^{\mathrm{T}}$ (Sneath \& Barrett, 1996), Neisseria animaloris LMG 23011 ${ }^{\mathrm{T}}$, Neisseria zoodegmatis LMG $23012^{\mathrm{T}}$ (Vandamme et al., 2006) and Neisseria weaveri CDC 8142 (Andersen et al., 1993) (note that N. weaveri Holmes et al. 1993 has priority over N. weaveri Andersen et al. 1993 and has a different type strain). The nucleotide similarities ranged from $98.35 \%$ for N. canis ATCC $14687^{\mathrm{T}}$ to $96.25 \%$ for $N$. weaveri CDC 8142 over $1311-1455 \mathrm{nt}$. Pairwise comparisons of the 16S rRNA gene sequence between strains $871^{\mathrm{T}}$ and 12337 revealed $99.86 \%$ similarity over $1463 \mathrm{nt}$. Strain $871^{\mathrm{T}}$ harboured three polymorphisms: two purine-to-purine substitutions and one pyrimidineto-pyrimidine substitution. One set of polymorphisms matched the sequence of strain 12337, so these sites are considered a match when the two sequences are compared. The closest type strain to strains 12337 and $871^{\mathrm{T}}$ was that of $N$. canis; followed by $N$. dentiae, N. zoodegmatis, $N$. weaveri and $N$. animaloris, with similarities ranging from $98.55 \%$ for $N$. canis to $96.75 \%$ for $N$. animaloris over $1455-1329 \mathrm{nt}$. The sequences of strains $9715^{\mathrm{T}}$ and 2507 were 97.88 and $97.68 \%$ similar to the sequences of strains $871^{\mathrm{T}}$ and 12337 , respectively.

As recommended by Tindall et al. (2010), DNA-DNA hybridization was performed between our clinical isolates and type strains exhibiting more than $97 \%$ 16S rRNA gene

Table 1. Strains used in this study

All four strains were isolated in New York State, USA.

\begin{tabular}{|c|c|c|}
\hline Strain & Source & Isolation date \\
\hline \multicolumn{3}{|l|}{ Neisseria wadsworthii sp. nov. } \\
\hline $9715^{\mathrm{T}}\left(=\right.$ DSM $22247^{\mathrm{T}}=$ CIP $\left.109934^{\mathrm{T}}\right)$ & Hand wound, 39-year-old male; Rensselaer County & 16 Dec 2005 \\
\hline $2507(=$ DSM $22245=$ CIP 109931$)$ & Peritoneal fluid, 36-year-old female; Monroe County & 20 Mar 2005 \\
\hline \multicolumn{3}{|l|}{ Neisseria shayeganii sp. nov. } \\
\hline $871^{\mathrm{T}}\left(=\mathrm{DSM} 22246^{\mathrm{T}}=\right.$ CIP $\left.109933^{\mathrm{T}}\right)$ & Sputum, 77-year-old female; Schenectady County & 7 Feb 2008 \\
\hline $12337(=$ DSM $22244=$ CIP 109932) & Arm wound, 47-year-old female; Westchester County & 9 Sep 2004 \\
\hline
\end{tabular}


sequence similarity. Spectroscopic DNA-DNA hybridization was performed in duplicate on DNA that was isolated using a French pressure cell (Thermo Spectronic) and purified by chromatography on hydroxyapatite (Cashion et al., 1977). DNA-DNA hybridization was carried out as described by De Ley et al. (1970) under consideration of the modifications described by Huß et al. (1983) using a model Cary 100 Bio UV/Vis spectrophotometer equipped with a Peltier-thermostatted $6 \times 6$ multicell changer and a temperature controller with in-situ temperature probe (Varian). The hybridization values, in duplicate, between strains $9715^{\mathrm{T}}$ and $871^{\mathrm{T}}$ and to type strains showing more than $97 \% 16 \mathrm{~S}$ rRNA gene sequence similarity are shown in Table 2. Based on a cut-off of $70 \%$ hybridization for defining species (Wayne et al., 1987), strains $9715^{\mathrm{T}}$ and $871^{\mathrm{T}}$ represent distinct species and, furthermore, do not belong to the same species as any of the tested type strains. By contrast, strains $9715^{\mathrm{T}}$ and 2507 yielded hybridization values greater than $70 \%$, indicating they are members of the same species, as did strains $871^{\mathrm{T}}$ and 12337.

To obtain further support for the species designations of these clinical isolates, we obtained partial sequences of the $23 \mathrm{~S}$ rRNA gene for each isolate and N. canis ATCC $14687^{\mathrm{T}}$, $N$. weaveri DSM $17688^{\mathrm{T}}, N$. dentiae DSM $19151^{\mathrm{T}}, N$. animaloris DSM $21642^{\mathrm{T}}$ and N. zoodegmatis DSM $21643^{\mathrm{T}}$. The $23 \mathrm{~S}$ rRNA sequence was amplified using the forward primer 129F (5'-CCGAATGGGGAAACC-3'; E. coli positions 115-129) and the reverse primer $2241 \mathrm{R}\left(5^{\prime}-\right.$ ACCGCCCCAGTCAAACT-3'; 2241-2257) (adapted from Hunt et al., 2006). Amplification was performed using AmpliTaq polymerase Gold (Applied Biosystems) with a single cycle at $95{ }^{\circ} \mathrm{C}$ for 9 min followed by 40 cycles of $95{ }^{\circ} \mathrm{C}$ for $30 \mathrm{~s}, 55{ }^{\circ} \mathrm{C}$ for $1 \mathrm{~min}$ and $72{ }^{\circ} \mathrm{C}$ for $2 \mathrm{~min}$, with a final extension at $72{ }^{\circ} \mathrm{C}$ for $7 \mathrm{~min}$ and a $4{ }^{\circ} \mathrm{C}$ hold. The sequencing primers used were 129F, 2241R, 1602F (Ludwig et al., 1994), 473tR (5'-CTTTCCCTCACGGTACT-3'; Hunt et al., 2006) and 1399F (Van Camp et al., 1993). Product sizes ranged from 2091 to $2172 \mathrm{bp}$.

Table 2. DNA-DNA relatedness of the novel strains and related type strains

Values in parentheses represent duplicate measurements. ND, Not done; NA, not applicable.

\begin{tabular}{|lcc|}
\hline \multirow{2}{*}{ Strain } & \multicolumn{1}{c|}{ DNA-DNA hybridization (\%) } \\
\cline { 2 - 3 } & $\mathbf{9 7 1 5}^{\mathbf{T}}$ & $\mathbf{8 7 1}^{\mathbf{T}}$ \\
\hline 2507 & $96.3(94.0)$ & $\mathrm{ND}$ \\
$871^{\mathrm{T}}$ & $37.6(40.2)$ & $\mathrm{NA}$ \\
12337 & $\mathrm{ND}$ & $84.9(87.9)$ \\
N. canis DSM $18000^{\mathrm{T}}$ & $51.6(52.8)$ & $17.1(20.5)$ \\
N. dentiae DSM $19151^{\mathrm{T}}$ & $33.9(40.3)$ & $4.2(13.8)$ \\
N. animaloris DSM $21642^{\mathrm{T}}$ & $41.8(33.8)$ & $\mathrm{ND}$ \\
N. zoodegmatis DSM $21643^{\mathrm{T}}$ & $\mathrm{ND}$ & $12.2(21.8)$ \\
N. weaveri DSM $17688^{\mathrm{T}}$ & $\mathrm{ND}$ & $28.9(34.0)$ \\
\hline
\end{tabular}

The 23S rRNA gene sequences of strains $9715^{\mathrm{T}}$ and 2507 were identical over $2093 \mathrm{nt}$, while the sequences of strains $871^{\mathrm{T}}$ and 12337 were $99.81 \%$ similar over $2172 \mathrm{nt}$ (see Supplementary Table S1, available in IJSEM Online). Strain $871^{\mathrm{T}}$ had a single polymorphism, a purine-to-purine substitution. Interestingly, strains $871^{\mathrm{T}}$ and 12337 each had a $78 \mathrm{nt}$ insertion at a site corresponding to E. coli position 1179. This insertion was absent from all other Neisseria strains for which 23S rRNA gene sequences are available in GenBank: these include strains $9715^{\mathrm{T}}$ and 2507 and the type strains of $N$. canis, $N$. weaveri, $N$. dentiae, $N$. animaloris and $N$. zoodegmatis sequenced in this study and Neisseria meningitidis Z2491 (Parkhill et al., 2000) and Neisseria gonorrhoeae NCCP 11945 (Chung et al., 2008). The insertion was omitted when we calculated sequence similarity. The sequences of strains $9715^{\mathrm{T}}$ and 2507 were most similar to that of N. canis ATCC $14687^{\mathrm{T}}$ (98.38\%). The sequences of strains $871^{\mathrm{T}}$ and 12337 were most similar to those of strains $9715^{\mathrm{T}}$ and $2507(97.23 \%)$. Other similarities are detailed in Supplementary Table S1. Thus, $23 \mathrm{~S}$ rRNA gene sequence analysis provides additional support that strains $9715^{\mathrm{T}}$ and 2507 are members of the same species, as are strains $871^{\mathrm{T}}$ and 12337.

CFA analysis was undertaken from isolates cultured for 24$48 \mathrm{~h}$ at $37{ }^{\circ} \mathrm{C}$ in air on TSBA plates. Fatty acid methyl esters were prepared according to the manufacturer's instructions (Sherlock Microbial Identification System; MIDI Corporation) and were identified using an Agilent Technologies $6890 \mathrm{~N}$ gas chromatograph. Only minor differences were observed between strains $9715^{\mathrm{T}}$ and 2507 and between strains $871^{\mathrm{T}}$ and 12337 (Table 3). In isolates $9715^{\mathrm{T}}$ and 2507 , the levels of $16: 0$ were reduced and the levels of $18: 1 \omega 7 c$ and summed feature $3(16: 1 \omega 7 c$ and/or iso-15:0 2-OH) were increased compared with $N$. canis ATCC $14687^{\mathrm{T}}$, resulting in a distinctive pattern. However, overall, the three most abundant fatty acids, $16: 0,18: 1 \omega 7 c$ and summed feature 3 , were the same as for $N$. canis ATCC $14687^{\mathrm{T}}$ and other closely related type strains (those of $N$. zoodegmatis, $N$. animaloris, $N$. dentiae and $N$. weaveri). In contrast, strains $871^{\mathrm{T}}$ and 12337 had a distinctive pattern of CFA abundance, in which 16:0 comprised over half of the fatty acids, $18: 1 \omega 7 c$ was greatly reduced and four additional fatty acids, present at similar levels, made up most of the rest of the total fatty acids.

Strains $9715^{\mathrm{T}}$ and 2507 were indistinguishable based on molecular and phenotypic analysis (see species description). As an aid in distinguishing these isolates from one another, PFGE was performed as described by Popovic et al. (2001) (Supplementary Fig. S1). After digestion of DNA with either Sfil, SpeI or NheI, fewer than three band differences were seen between $9715^{\mathrm{T}}$ and 2507 ; this level of difference is interpreted as closely related (Tenover et al., 1995). However, differences between strain $9715^{\mathrm{T}}$ or 2507 and N. canis ATCC $14687^{\mathrm{T}}$ were very pronounced, with few apparent matches.

Based on $16 \mathrm{~S}$ and $23 \mathrm{~S}$ rRNA gene sequences, DNA-DNA hybridization, CFA composition and phenotypic analysis 
Table 3. Fatty acid compositions of the novel strains and related type strains

Strains: $1,871^{\mathrm{T}} ; 2,12337 ; 3,9715^{\mathrm{T}} ; 4,2507 ; 5$, N. canis ATCC $14687^{\mathrm{T}} ; 6$, N. dentiae DSM $19151^{\mathrm{T}} ; 7$, N. weaveri DSM 17688 ${ }^{\mathrm{T}} ; 8$, N. animaloris DSM $21642^{\mathrm{T}} ; 9$, N. zoodegmatis DSM $21643^{\mathrm{T}}$. Values are percentages of total CFAs; fatty acid methyl esters for which no values were greater than $1 \%$ have been omitted. The three most abundant fatty acids for each isolate are in bold. ND, Not detected.

\begin{tabular}{|c|c|c|c|c|c|c|c|c|c|}
\hline Fatty acid & 1 & 2 & 3 & 4 & 5 & 6 & 7 & 8 & 9 \\
\hline $12: 0$ & 7.97 & 6.83 & 4.96 & 4.95 & 5.56 & 6.56 & 5.21 & 8.22 & 6.29 \\
\hline $12: 03-\mathrm{OH}$ & 8.71 & 7.35 & 3.37 & 3.54 & 3.84 & 4.25 & 3.15 & 4.81 & 4.1 \\
\hline $14: 0$ & 7.54 & 11.17 & 1.99 & 1.86 & 6.68 & 4.24 & 6.29 & 8.16 & 5.61 \\
\hline Summed feature $2^{*}$ & ND & $\mathrm{ND}$ & 2.02 & 2.04 & 2.77 & 3.14 & 2.00 & 2.56 & 2.34 \\
\hline Summed feature $3^{\star}$ & 11.07 & 14.22 & 28.45 & 28.00 & 23.33 & 22.76 & 37.24 & 29.73 & 30.04 \\
\hline $16: 1 \omega 5 c$ & ND & $\mathrm{ND}$ & $\mathrm{ND}$ & $\mathrm{ND}$ & $\mathrm{ND}$ & 0.73 & 2.88 & 1.4 & 0.93 \\
\hline $16: 0$ & 57.15 & 55.97 & 33.3 & 32.83 & 35.85 & 30.53 & 17.89 & 26.56 & 32.08 \\
\hline $16: 02-\mathrm{OH}$ & 0.51 & ND & $\mathrm{ND}$ & ND & 1.52 & 3.03 & $\mathrm{ND}$ & ND & 2.26 \\
\hline $16: 03-\mathrm{OH}$ & 1.24 & 1.17 & ND & ND & 0.41 & 0.31 & $\mathrm{ND}$ & $\mathrm{ND}$ & 0.17 \\
\hline $18: 1 \omega 9 c$ & 1.84 & $\mathrm{ND}$ & ND & ND & $\mathrm{ND}$ & $\mathrm{ND}$ & ND & ND & ND \\
\hline $18: 1 \omega 7 c$ & 2.45 & 3.28 & 24.4 & 25.15 & 19.19 & 23.15 & 24.27 & 17.45 & 15.56 \\
\hline $18: 0$ & 0.87 & $\mathrm{ND}$ & 1.07 & 1.13 & 0.65 & 0.36 & $\mathrm{ND}$ & 0.28 & 0.18 \\
\hline
\end{tabular}

${ }^{\star}$ Summed features consist of groups of two or three fatty acids that cannot be separated using the MIDI System. Summed feature 2 is composed of iso-16:1 I and/or 14:0 3-OH; summed feature 3 is composed of $16: 1 \omega 7 c$ and/or iso-15:0 2-OH.

(see species description and Table 4), we propose that strains $9715^{\mathrm{T}}$ and 2507 are representatives of a single species, Neisseria wadsworthii sp. nov. Similarly, 12337 and $871^{\mathrm{T}}$ represent a single species, Neisseria shayeganii sp. nov. Strain differences for $N$. wadsworthii sp. nov. were revealed only by PFGE, while the N. shayeganii sp. nov. strains could be distinguished based on 16S rRNA gene sequence divergence of $0.14 \%$, a level which is consistent with intraspecies variation for Neisseria species (Clarridge, 2004). For the designated type strains of both $N$. wadsworthii sp. nov. and N. shayeganii sp. nov., DNADNA hybridization levels to type strains with more than $97 \% 16 \mathrm{~S}$ rRNA gene sequence similarity were well below the species threshold of $70 \%$ (Wayne et al., 1987), justifying the designation of both isolates as representatives of novel species.

Additional features that help to distinguish N. wadsworthii sp. nov. and N. shayeganii sp. nov. from one another and from other closely related taxa characterized in this study are shown in Table 4 and can be summarized as follows: (i) production of acid from D-glucose in Gordon base medium by $N$. wadsworthii sp. nov. (see species description); (ii) production of acid from peptone water base with $1 \%$ L-arabinose by $N$. canis, but not by either $N$. wadsworthii sp. nov. or N. shayeganii sp. nov.; (iii) reaction patterns for API NH and API ZYM strips (bioMérieux), for which the alkaline phosphatase and valine arylamidase reactions are particularly useful; (iv) rod-shaped cells in $N$. shayeganii sp. nov. (see species description and Supplementary Fig. S2), a character that is unusual for Neisseria and is shared only with Neisseria elongata, N. weaveri and Neisseria bacilliformis (Andersen et al., 1993; Bøvre \& Holten, 1970; Han et al., 2006); (v) small, light yellow-grey colonies for $N$. shayeganii sp. nov. compared with larger, yellow colonies for $N$. canis and $N$. wadsworthii sp. nov. (Supplementary Fig. S2); (vi) a $78 \mathrm{nt}$ insertion in the $23 \mathrm{~S}$ rRNA gene sequence of strains of $N$. shayeganii sp. nov. that is absent from all other Neisseria strains examined so far; and (vii) the distinctive CFA composition of $N$. shayeganii sp. nov. compared with those of neighbouring taxa.

$N$. wadsworthii sp. nov. and $N$. shayeganii sp. nov. are distinguished from most other species of Neisseria with validly published names by the absence of acid production from various sugars and/or the ability to reduce nitrate (Tønjum, 2005). Exceptions are Neisseria iguanae, which is distinguished by the absence of anaerobic growth and the presence of $\alpha$-haemolysis, $N$. elongata subsp. glycolytica, which is distinguished by the ability to grow on MacConkey agar, N. elongata subsp. nitroreducens, which is distinguished by the absence of catalase activity, and $N$. bacilliformis, in which isolates are distinguished by the absence of either catalase activity or nitrate-reducing activity (Han et al., 2006; Weyant et al., 1984). Furthermore, N. wadsworthii sp. nov. and N. shayeganii sp. nov. are distinguished from the type species of the genus, $N$. gonorrhoeae, by phylogenetic analysis of the $16 \mathrm{~S}$ rRNA gene sequence (Fig. 1), showing that the novel species reside in a separate clade, 23S rRNA gene sequence distances (Supplementary Table S1), different relative abundances of predominant CFAs (Weyant et al., 1984) and the inability of strains of the novel species to produce acid from glucose and their ability to reduce nitrate (Tønjum, 2005).

Characteristics that support inclusion of our isolates in the genus Neisseria are Gram-negative staining, catalase and oxidase activity, the absence of motility and CFA profiles (Tønjum, 2005; Weyant et al., 1984). Additionally, 
Table 4. Characteristics that distinguish the novel strains from the type strains of neighbouring taxa

Strains: $1,871^{\mathrm{T}} ; 2,12337 ; 3,9715^{\mathrm{T}} ; 4,2507 ; 5$, N. canis ATCC $14687^{\mathrm{T}}$; 6, N. dentiae DSM $19151^{\mathrm{T}} ; 7, N$. weaveri DSM $17688^{\mathrm{T}} ; 8, N$. animaloris DSM $21642^{\mathrm{T}} ; 9, \mathrm{~N}$. zoodegmatis DSM $21643^{\mathrm{T}}$. v, Variable.

\begin{tabular}{|c|c|c|c|c|c|c|c|c|c|}
\hline Characteristic & 1 & 2 & 3 & 4 & 5 & 6 & 7 & 8 & 9 \\
\hline Nitrate reduction & + & + & + & + & + & - & - & + & + \\
\hline Arginine dihydrolase & - & - & + & - & - & - & - & + & - \\
\hline \multicolumn{10}{|l|}{ Acid production from $(\mathrm{O}-\mathrm{F})$ : } \\
\hline D-Glucose & - & - & - & - & - & + & - & - & + \\
\hline D-Mannitol & - & - & - & - & - & + & - & - & - \\
\hline Sucrose & - & - & - & - & - & + & - & - & - \\
\hline D-Xylose & - & - & - & - & - & + & - & - & - \\
\hline D-Fructose & - & - & $\mathrm{V}$ & - & - & + & - & - & - \\
\hline \multicolumn{10}{|l|}{$\begin{array}{l}\text { Acid production from (peptone } \\
\text { water): }\end{array}$} \\
\hline L-Arabinose & - & - & - & - & + & - & - & - & - \\
\hline D-Glucose & + & - & - & - & - & + & - & + & + \\
\hline Sucrose & - & - & - & - & - & + & - & - & - \\
\hline \multicolumn{10}{|c|}{ Acid production from (Gordon): } \\
\hline D-Glucose & - & - & + & + & - & + & - & + & + \\
\hline D-Mannitol & - & - & - & - & - & + & - & - & - \\
\hline Sucrose & - & - & - & - & - & + & - & - & - \\
\hline D-Fructose & - & - & - & - & - & + & - & - & - \\
\hline Trehalose & - & - & - & - & - & + & - & - & - \\
\hline D-Mannose & - & - & - & - & - & + & - & - & - \\
\hline \multicolumn{10}{|l|}{ Acidification of (API NH): } \\
\hline D-Fructose & - & - & - & - & - & + & - & + & - \\
\hline Sucrose & - & - & - & - & - & + & - & - & - \\
\hline L-Ornithine decarboxylase & - & - & - & - & - & - & - & + & - \\
\hline \multicolumn{10}{|l|}{ Hydrolysis of (API NH): } \\
\hline $\begin{array}{l}\text { Proline } 4 \text {-methoxy- } \beta \text { - } \\
\text { naphthylamide }\end{array}$ & - & + & + & + & + & - & + & & + \\
\hline $\begin{array}{l}\gamma \text {-Glutamyl 4-methoxy- } \beta \text { - } \\
\text { naphthylamide }\end{array}$ & + & + & + & - & - & + & - & & + \\
\hline \multicolumn{10}{|l|}{ API ZYM results } \\
\hline Alkaline phosphatase & + & + & - & - & + & + & + & + & + \\
\hline Esterase lipase (C8) & + & + & + & + & + & - & - & - & - \\
\hline Valine arylamidase & - & - & + & + & + & - & - & & - \\
\hline Cystine arylamidase & + & + & + & + & + & - & + & - & + \\
\hline
\end{tabular}

phylogenetic analysis provides strong support for the assignment of $N$. wadsworthii sp. nov. and $N$. shayeganii sp. nov. to a clade containing N. canis, N. dentiae and N. bacilliformis (Fig. 1). A neighbour-joining phylogenetic tree was generally concordant with the Bayesian tree, although the bootstrap support was weaker (not shown). However, the genus Neisseria is polyphyletic; therefore, when novel species are assigned to the genus, membership of closely related genera should be excluded based on multiple criteria. N. wadsworthii sp. nov. and N. shayeganii sp. nov. are as distant from some species of Eikenella, Kingella, Alysiella, Uruburuella, Bergeriella, Conchiformibium and Simonsiella as they are from some of the other more distantly related Neisseria species. The presence of catalase activity and the absence of motility observed in our isolates exclude membership of the genera Bergeriella, Eikenella and Kingella, which are catalase-negative. These characteristics also exclude from consideration the genera Simonsiella, Alysiella and Conchiformibium, whose members form long filaments and display gliding motility. These genera are further excluded from consideration because they reside in well-supported clades separate from the clade made up by $N$. wadsworthii sp. nov. and $N$. shayeganii sp. nov. The single species of Uruburuella produces acid from fructose and glucose, a feature that, along with its 16S rRNA gene sequence, clearly distinguishes it from our isolates. At this time, there exist no clear phenotypic grounds on which to distinguish the genus Uruburuella from the genus Neisseria (Vandamme et al., 2006). Therefore, until characters are described that permit unambiguous differentiation of the two genera, we deem it prudent, based on our analysis, to include our isolates in the genus Neisseria.

\section{Description of Neisseria wadsworthii sp. nov.}

Neisseria wadsworthii (wads.wor'thi.i. N.L. gen. n. wadsworthii of the Wadsworth Center, to recognize the service provided to New York State residents by the Bacteriology Laboratory of the New York State Department of Health's Wadsworth Center and its role as a public health resource).

Colonies are small, circular, entire, convex, moist, light yellow to orange and non-haemolytic. Cells are Gramnegative, coccoid, 1.3-1.8 $\mu \mathrm{m}$ in diameter, and may be present in pairs and chains. Growth is observed between 10 and $42{ }^{\circ} \mathrm{C}$. No growth is observed on MacConkey agar after 5 days. Facultative anaerobe. Cells produce catalase and cytochrome oxidase and reduce nitrate to nitrite. Both known isolates produce acid from D-glucose after 10 days on a Gordon base containing $10 \%$ D-glucose. Negative for acid production using Hugh and Leifson oxidationfermentation (O-F) base with $1 \% \mathrm{D}$-fructose, D-glucose, lactose, maltose, D-mannitol, sucrose or D-xylose. Negative for acid production in peptone water base with $1 \%$ adonitol, L-arabinose, dulcitol, D-glucose, inositol, lactose, maltose, D-mannitol, raffinose, D-rhamnose, D-salicin, Dsorbitol, sucrose or D-xylose. Negative for acid production (Gordon sugar base containing $10 \%$ carbohydrate) from Larabinose, cellobiose, dulcitol, D-fructose, D-galactose, glycerol, inositol, inulin, lactose, maltose, D-mannitol, Dmannose, melibiose, raffinose, D-rhamnose, D-salicin, Dsorbitol, sucrose, trehalose or D-xylose. Negative for utilization of Simmons' citrate, hydrolysis of aesculin, urea and gelatin, indole production, decarboxylation of arginine, lysine and ornithine using Moeller's decarboxylase medium and production of $\mathrm{H}_{2} \mathrm{~S}$ in triple-sugar iron agar (for details of methods, see Forbes et al., 1998; Gordon et al., 1973; Kohlerschmidt et al., 2009). Using the API NH system, both known isolates are positive for proline arylamidase and acidification of $\mathrm{D}$-glucose and negative for penicillinase, acidification of D-fructose, maltose and sucrose, ornithine decarboxylase, urease, lipase, alkaline phosphatase, $\beta$-galactosidase and hydrolysis of indole; variable for $\gamma$-glutamyltransferase (type strain positive). 


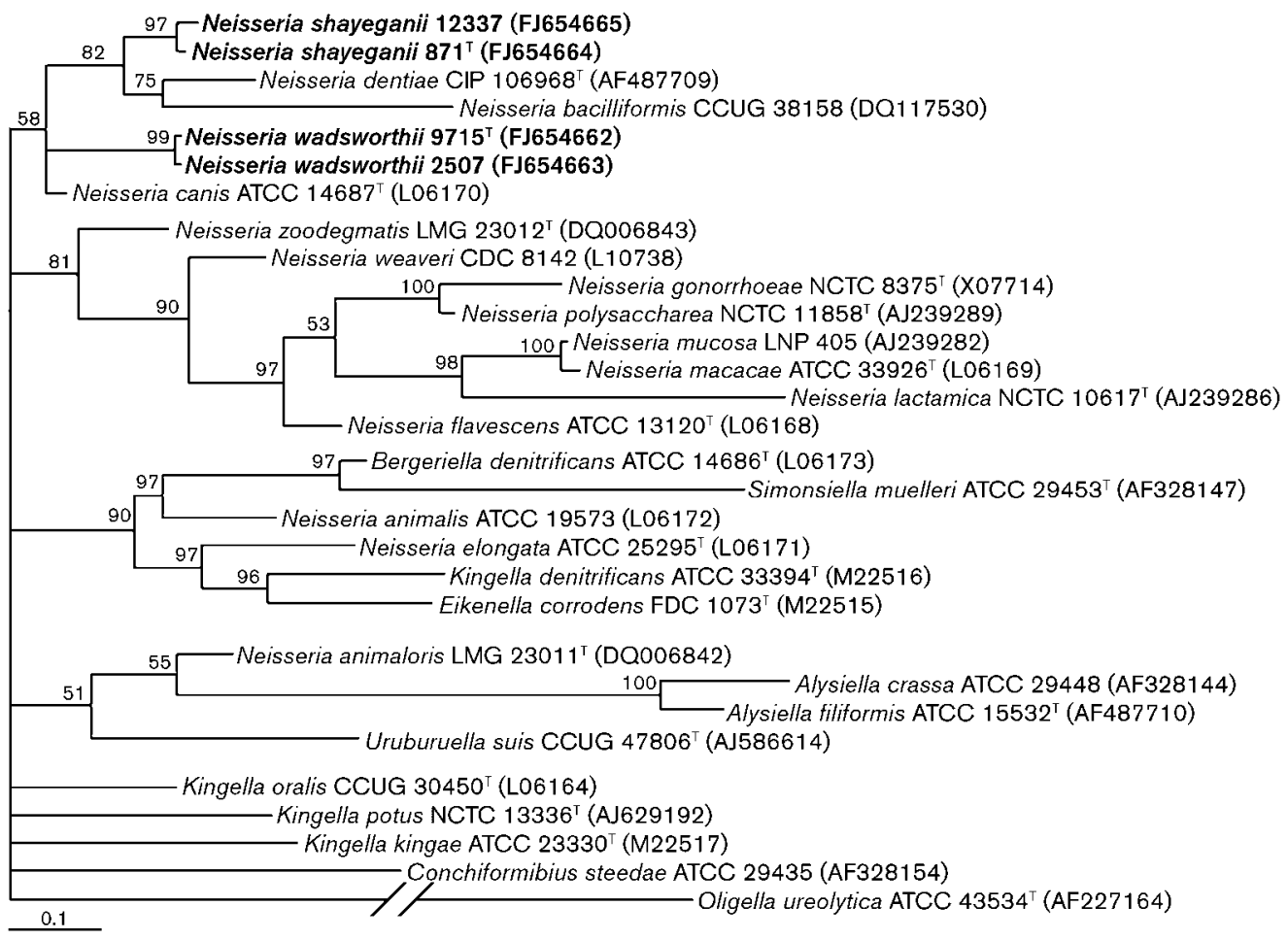

Fig. 1. Bayesian phylogenetic tree from a 1307-position 16S rRNA gene sequence alignment, showing the positions of strains of Neisseria wadsworthii sp. nov. and Neisseria shayeganii sp. nov., relative to previously described species and genera. Posterior probabilities of nodes are indicated. The branch for the outgroup Oligella ureolytica ATCC $43534^{\top}$ is shown at $1 / 10$ actual length. Branches with posterior probabilities of less than $50 \%$ were collapsed. Bar, 0.1 expected changes per site.

Using the API ZYM system, both known isolates are positive for esterase (C4), esterase lipase (C8), leucine arylamidase, valine arylamidase, cystine arylamidase, acid phosphatase and naphthol-AS-BI-phosphohydrolase and negative for alkaline phosphatase, lipase (C14), trypsin, $\alpha$ chymotrypsin, $\alpha$-galactosidase, $\beta$-galactosidase, $\beta$-glucuronidase, $\alpha$-glucosidase, $\beta$-glucosidase, $N$-acetyl- $\beta$-glucosaminidase, $\alpha$-mannosidase and $\alpha$-fucosidase. The predominant CFAs for both known strains are 16:0, summed feature 3 $(16: 1 \omega 7 c$ and/or iso-15:0 2-OH) and $18: 1 \omega 7 c$.

The type strain, $9715^{\mathrm{T}}\left(=\mathrm{DSM} 22247^{\mathrm{T}}=\right.$ CIP $\left.109934^{\mathrm{T}}\right)$, was isolated from a hand wound of a 39 -year old male in New York, USA. Reference strain 2507 (=DSM 22245 $=$ CIP 109931) was isolated from peritoneal fluid of a 36year old female in New York, USA.

\section{Description of Neisseria shayeganii sp. nov.}

Neisseria shayeganii (sha.ye.ga' ni.i. N.L. gen. n. shayeganii of Shayegani, to recognize and honour over 40 years of public service and leadership by Dr Mehdi Shayegani in the Bacteriology Laboratory of the Wadsworth Center, New York State Department of Health).

Colonies are small, circular, entire, convex, moist, light yellow to grey and non-haemolytic. Cells are Gram-negative, rod-shaped and $1.0-1.5 \mu \mathrm{m}$ wide by $2.5-5.5 \mu \mathrm{m}$ long. Growth is observed between 10 and $42{ }^{\circ} \mathrm{C}$. No growth is observed on MacConkey agar after 5 days. Facultative anaerobe. Cells produce catalase and cytochrome oxidase and they reduce nitrate to nitrite. Negative for acid production using Hugh and Leifson O-F base with $1 \%$ Dfructose, D-glucose, lactose, maltose, D-mannitol, sucrose or D-xylose. Except as noted, negative for acid production in peptone water sugar (containing $1 \%$ carbohydrate) from adonitol, L-arabinose, dulcitol, D-glucose (positive for strain $871^{\mathrm{T}}$ ), inositol, lactose, maltose, D-mannitol, raffinose, D-rhamnose, D-salicin, D-sorbitol, sucrose or D-xylose. Negative for acid production (Gordon sugars) from L-arabinose, cellobiose, dulcitol, D-fructose, D-galactose, D-glucose, glycerol, inositol, inulin, lactose, maltose, Dmannitol, D-mannose, melibiose, raffinose, D-rhamnose, Dsalicin, D-sorbitol, sucrose, trehalose and D-xylose. Negative for utilization of Simmons' citrate, hydrolysis of aesculin, urea and gelatin, indole production, decarboxylation of lysine, ornithine and arginine using Moeller's decarboxylase medium and production of $\mathrm{H}_{2} \mathrm{~S}$ in triple-sugar iron agar (Forbes et al., 1998; Gordon et al., 1973; Kohlerschmidt et al., 2009). Using the API NH system, both known strains are positive for $\gamma$-glutamyltransferase and acidification of Dglucose and negative for penicillinase, acidification of Dfructose, maltose and sucrose, ornithine decarboxylase, 
urease, lipase, alkaline phosphatase, $\beta$-galactosidase and indole; variable for proline arylamidase (type strain negative). Using the API ZYM system, both known strains are positive for alkaline phosphatase, esterase (C4), esterase lipase (C8), leucine arylamidase, cystine arylamidase, acid phosphatase and naphthol-AS-BI-phosphohydrolase and negative for lipase (C14), valine arylamidase, trypsin, $\alpha$-chymotrypsin, $\alpha$-galactosidase, $\beta$-galactosidase, $\beta$-glucuronidase, $\alpha$-glucosidase, $\beta$-glucosidase, $N$-acetyl- $\beta$-glucosaminidase and $\alpha$-mannosidase; variable for $\alpha$-fucosidase (type strain negative). The predominant CFAs for both known strains are $16: 0$, summed feature $3(16: 1 \omega 7 \mathrm{c}$ and/or iso$15: 02-\mathrm{OH}), 12: 0,12: 03-\mathrm{OH}$ and $14: 0$.

The type strain, $871^{\mathrm{T}}\left(=\mathrm{DSM} 22246^{\mathrm{T}}=\mathrm{CIP} 109933^{\mathrm{T}}\right)$, was isolated from sputum of a 77-year-old female in New York, USA. Reference strain 12337 (=DSM $22244=$ CIP 109932) was isolated from an arm wound of a 47-year-old female in New York, USA.

\section{Acknowledgements}

We thank the Wadsworth Center Applied Genomic Technologies Core for sequencing, Michelle Dickinson, Tanya Halse, Teresa Passaretti, Tammy Quinlan, Lisa Thompson and Danielle Wroblewski for help in establishing our collection of unidentified bacteria and Yvette Khachadourian for assistance with PFGE. We also wish to thank George Hannett and Daniel Garcia for useful discussions and Adriana Verschoor for editing. We also wish to thank Bettina Sträubler from the Deutsche Sammlung von Mikroorganismen und Zellkulturen GmbH for excellent technical assistance.

\section{References}

Altschul, S. F., Madden, T. L., Schaffer, A. A., Zhang, J., Zhang, Z., Miller, W. \& Lipman, D. J. (1997). Gapped BLAST and PSI-BLAST: a new generation of protein database search programs. Nucleic Acids Res 25, 3389-3402.

Andersen, B. M., Steigerwalt, A. G., O'Connor, S. P., Hollis, D. G., Weyant, R. S., Weaver, R. E. \& Brenner, D. J. (1993). Neisseria weaveri sp. nov., formerly CDC group $\mathrm{M}-5$, a gram-negative bacterium associated with dog bite wounds. J Clin Microbiol 31, 2456-2466.

Berger, U. \& Paepcke, E. (1962). Studies on asaccharolytic Neisseria in the human nasopharynx. Z Hyg Infektionskr 148, 269-281.

Bøvre, K. \& Holten, E. (1970). Neisseria elongata sp. nov., a rodshaped member of the genus Neisseria. Re-evaluation of cell shape as a criterion in classification. J Gen Microbiol 60, 67-75.

Cashion, P., Holder-Franklin, M. A., McCully, J. \& Franklin, M. (1977). A rapid method for the base ratio determination of bacterial DNA. Anal Biochem 81, 461-466.

Chun, J., Lee, J. H., Jung, Y., Kim, M., Kim, S., Kim, B. K. \& Lim, Y. W. (2007). EzTaxon: a web-based tool for the identification of prokaryotes based on $16 \mathrm{~S}$ ribosomal RNA gene sequences. Int J Syst Evol Microbiol 57, 2259-2261.

Chung, G. T., Yoo, J. S., Oh, H. B., Lee, Y. S., Cha, S. H., Kim, S. J. \& Yoo, C. K. (2008). Complete genome sequence of Neisseria gonorrhoeae NCCP11945. J Bacteriol 190, 6035-6036.

Clarridge, J. E., III (2004). Impact of $16 \mathrm{~S}$ rRNA gene sequence analysis for identification of bacteria on clinical microbiology and infectious diseases. Clin Microbiol Rev 17, 840-862.
De Ley, J., Cattoir, H. \& Reynaerts, A. (1970). The quantitative measurement of DNA hybridization from renaturation rates. Eur $J$ Biochem 12, 133-142.

Forbes, B. A., Sahm, D. F. \& Weissfeld, A. S. (1998). Overview of bacterial identification methods and strategies. In Bailey and Scott's Diagnostic Microbiology, 10th edn, pp. 424-446. Edited by J. Roche. St Louis, MO: Mosby.

Gordon, R. E., Haynes, W. C. \& Pang, C. H. (1973). Media and methods. In The Genus Bacillus, US Department of Agriculture Handbook no. 427, pp. 2-14. Washington, DC: US Government Printing Office.

Han, X. Y., Hong, T. \& Falsen, E. (2006). Neisseria bacilliformis sp. nov. isolated from human infections. J Clin Microbiol 44, 474-479.

Holmes, B., Costas, M., On, S. L. W., Vandamme, P., Falsen, E. \& Kersters, K. (1993). Neisseria weaveri sp. nov. (formerly CDC group M-5), from dog bite wounds of humans. Int J Syst Bacteriol 43, 687693.

Hunt, D. E., Klepac-Ceraj, V., Acinas, S. G., Gautier, C., Bertilsson, S. \& Polz, M. F. (2006). Evaluation of 23 S rRNA PCR primers for use in phylogenetic studies of bacterial diversity. Appl Environ Microbiol 72, 2221-2225.

Huß, V. A. R., Festl, H. \& Schleifer, K. H. (1983). Studies on the spectrophotometric determination of DNA hybridization from renaturation rates. Syst Appl Microbiol 4, 184-192.

Kohlerschmidt, D. J., Musser, K. A. \& Dumas, N. B. (2009). Identification of aerobic Gram-negative bacteria. In Practical Handbook of Microbiology, 2nd edn, pp. 67-80. Edited by E. Goldman \& L. H. Green. Boca Raton, FL: CRC Press.

Ludwig, W., Dorn, S., Springer, N., Kirchhof, G. \& Schleifer, K. H. (1994). PCR-based preparation of $23 S$ rRNA-targeted group-specific polynucleotide probes. Appl Environ Microbiol 60, 3236-3244.

Parkhill, J., Achtman, M., James, K. D., Bentley, S. D., Churcher, C., Klee, S. R., Morelli, G., Basham, D., Brown, D. \& other authors (2000). Complete DNA sequence of a serogroup A strain of Neisseria meningitidis Z2491. Nature 404, 502-506.

Popovic, T., Schmink, S., Rosenstein, N. A., Ajello, G. W., Reeves, M. W., Plikaytis, B., Hunter, S. B., Ribot, E. M., Boxrud, D. \& other authors (2001). Evaluation of pulsed-field gel electrophoresis in epidemiological investigations of meningococcal disease outbreaks caused by Neisseria meningitidis serogroup C. J Clin Microbiol 39, 7585.

Ronquist, F. \& Huelsenbeck, J. P. (2003). MrBayes 3: Bayesian phylogenetic inference under mixed models. Bioinformatics 19, 15721574.

Sneath, P. H. \& Barrett, S. J. (1996). A new species of Neisseria from the dental plaque of the domestic cow, Neisseria dentiae sp. nov. Lett Appl Microbiol 23, 355-358.

Tenover, F. C., Arbeit, R. D., Goering, R. V., Mickelsen, P. A., Murray, B. E., Persing, D. H. \& Swaminathan, B. (1995). Interpreting chromosomal DNA restriction patterns produced by pulsed-field gel electrophoresis: criteria for bacterial strain typing. J Clin Microbiol 33, 2233-2239.

Tindall, B. J., Rosselló-Mora, R., Busse, H.-J., Ludwig, W. \& Kämpfer, P. (2010). Notes on the characterization of prokaryote strains for taxonomic purposes. Int J Syst Evol Microbiol 60, 249-266.

Tønjum, T. (2005). Genus I. Neisseria Trevisan $1885,105^{\mathrm{AL}}$. In Bergey's Manual of Systematic Bacteriology, 2nd edn, vol. 2C, pp. 777798. Edited by D. J. Brenner, N. R. Krieg, J. T. Staley \& G. M. Garrity. New York: Springer.

Van Camp, G., Chapelle, S. \& De Wachter, R. (1993). Amplification and sequencing of variable regions in bacterial $23 \mathrm{~S}$ ribosomal RNA 
genes with conserved primer sequences. Curr Microbiol 27, 147151.

Vandamme, P., Holmes, B., Bercovier, H. \& Coenye, T. (2006). Classification of Centers for Disease Control Group Eugonic Fermenter (EF)-4a and EF-4b as Neisseria animaloris sp. nov. and Neisseria zoodegmatis sp. nov., respectively. Int J Syst Evol Microbiol 56, 1801-1805.

Wayne, L. G., Brenner, D. J., Colwell, R. R., Grimont, P. A. D., Kandler, O., Krichevsky, M. I., Moore, L. H., Moore, W. E. C., Murray, R. G. E. \& other authors (1987). International Committee on Systematic Bacteriology. Report of the ad hoc committee on reconciliation of approaches to bacterial systematics. Int J Syst Bacteriol 37, 463-464.

Weyant, R. S., Moss, C. W., Weaver, R. E., Hollis, D. G., Jordan, J. G., Cook, E. C. \& Daneshvar, M. I. (1984). Identification of Unusual Pathogenic Gram-Negative Aerobic and Facultatively Anaerobic Bacteria, 2nd edn. Baltimore, MD: Williams \& Wilkins.

Zhang, Z., Schwartz, S., Wagner, L. \& Miller, W. (2000). A greedy algorithm for aligning DNA sequences. J Comput Biol 7, 203-214. 